\title{
Anaesthesia and Critical Care Department at a Major Academic Centre's Adaptation to Face the COVID-19 Pandemic
}

\author{
Sara Farsi (iD' \\ Nada Noaman' \\ Auhood Bukhary' \\ Wadeeah Bahaziq' \\ Alaa Sabbahi' \\ Ibrahim Abushoshah (D) \\ Abdulaziz Boker $\mathbb{D}^{1,2}$ \\ 'Anesthesia and Critical Care \\ Department, King Abdulaziz University \\ Hospital, Faculty of Medicine, King \\ Abdulaziz University, Jeddah, Saudi \\ Arabia; ${ }^{2}$ Clinical Skills and Simulation \\ Centre, King Abdulaziz University, \\ Jeddah, Saudi Arabia
}

\begin{abstract}
The new novel coronavirus is having a major impact on healthcare systems internationally. Hospitals are struggling to manage the sudden influx of critical patients. Anaesthesiologists and critical care physicians are front liners in the fight against COVID-19 and carry the highest risk of getting infected. Due to the rapid response of the Saudi government to the WHO's early warning, we were fortunate at our hospital to see a slower rise in COVID-19 cases allowing us some time to prepare. We had to make room for the expected rise in highly infectious and critical patients, while at the same time protecting nonCOVID-19 patients, staff and trainees. Additionally, the team continued to provide essential and specialized care to all patients in the hospital and maintain its academic and non-clinical services within the university. This review presents the different protocols, challenges and lessons learned during the development of a COVID-19 anaesthesia and critical care department plan in a major teaching hospital in Jeddah, Saudi Arabia. Our ultimate aim is to share our experience with other similar institutions.
\end{abstract}

Keywords: SARS-COV-2, airway team, infection prevention, hospital resource, management, crisis planning, medical education

\section{Introduction}

On the 30th of January 2020, World Health Organization (WHO) Director-General declared the novel coronavirus outbreak (2019-nCoV) a Public Health Emergency of International Concern. ${ }^{1}$ This virus emerged at a fish-market in Wuhan, China and rapidly spread across the globe soon leading to 118,319 confirmed cases and 4292 deaths all over the world. This massive international effect compelled the WHO to declare the disease a global pandemic on the 11th of March 2020. ${ }^{2}$ The COVID-19 virus has taken the whole world by surprise and is currently taking a huge toll on several sectors such as education, commerce, tourism, aviation and especially the healthcare systems.

COVID-19 has had a crippling effect on many healthcare systems. It carries a case fatality rate (CFR) of 5.7\%. Although it is a lot lower than two similar viruses, SARS 9.6\% CFR and MERS $34.4 \%$ CFR, ${ }^{3,4}$ the concern comes from the rapid human-tohuman transmission. It's transmitted by droplet and has a basic reproductive number of 2.34-3.58 and can survive on surfaces for an extended length of time. ${ }^{5}$ Although it carries a low fatality rate it has a hospitalization rate of $4.4 \%$, with $30 \%$ of those hospitalized requiring critical care or extracorporeal membrane oxygenation. ${ }^{6}$ These properties place a large burden on various aspects of the healthcare system. The
Correspondence: Abdulaziz Boker Department of Anesthesia and Critical Care, Clinical Skills and Simulation Centre, Faculty of Medicine, King Abdulaziz University, P.B. Box 80215, Jeddah, 21589, Saudi Arabia Tel +966-2-640-1000 (ext. I-10199/ 10209)

Fax+966-2-640-8335

Email aboker@kau.edu.sa 


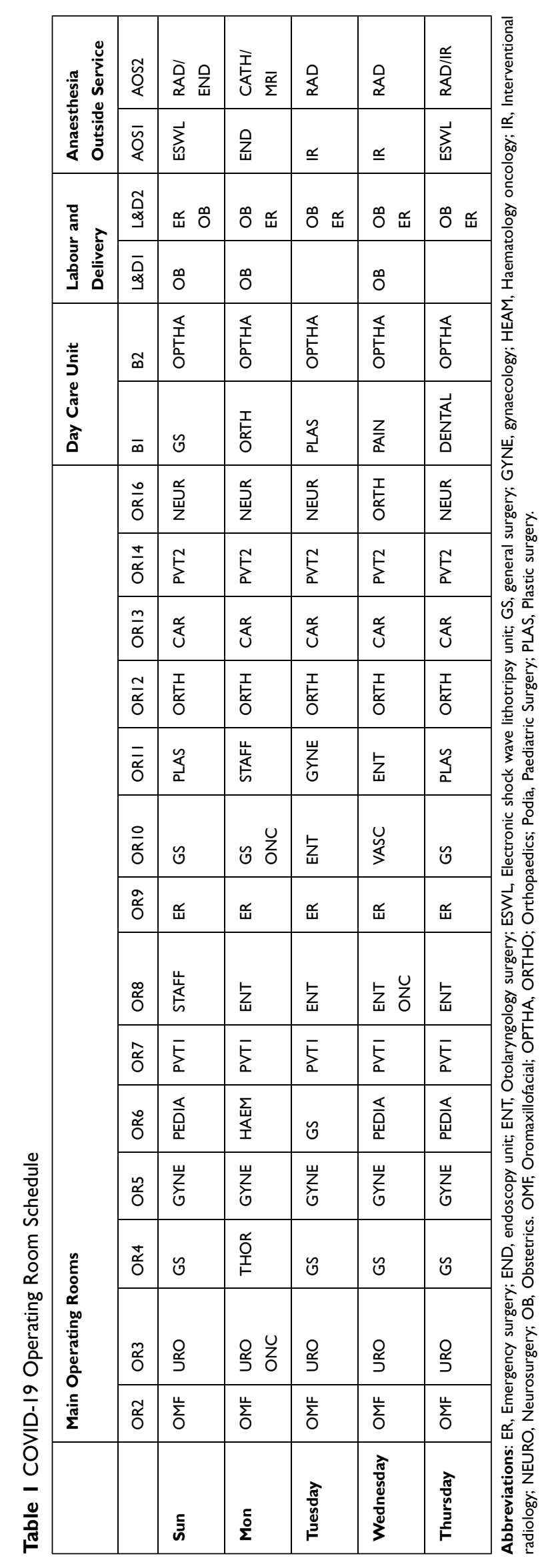


Lombardy region, one of the hardest hit provinces in Italy, has a capacity of 724 intensive care unit beds and was faced with 1006 COVID-19 patients requiring mechanical ventilation. $^{7}$

Healthcare workers in Spain were faced with a shortage of personal protective equipment leading to reuse despite the acknowledged risk. ${ }^{8}$ In the UK, it was estimated that absence of healthcare staff due to illness or self-isolation may reach as high as $20 \%$. Consequently, doctors who had retired in the last 3 years were asked to return to work and medical students in their final year graduated early to join the workforce. ${ }^{9}$ Furthermore, hospital-related transmission was suspected in $41 \%$ of patients in Wuhan, China. The risk is even higher for healthcare workers involved in aerosol generating procedures. ${ }^{10}$ As a response to these and many other issues facing the healthcare system the WHO released the international community's "Strategic Preparedness and Response Plan" to help protect states with weaker health systems. ${ }^{1}$ The staff at King Abdulaziz University Hospital (KAUH) realized that sooner or later COVID-19 patients would start filling their wards and they had to start preparing.

KAUH is the largest tertiary hospital in the western region of Saudi Arabia. Structurally, it has a 1000 bed capacity. Prior to the start of the pandemic in March 2020, it ran 650 inpatient beds. Those hospital beds were divided between the medical specialties, paediatrics, obstetrics as well as surgical specialties. All areas had to be prepared for facing the oncoming pandemic. One area of particular concern for the anaesthesia team was the operating rooms.

The operating rooms at KAUH are located in three areas: the main operating rooms with 16 fully functioning operating rooms, a separate day surgery unit containing 4 operating rooms and a labour and delivery unit containing 2 operating rooms. Each area has its own post-operative recovery unit. We had a total of 18 operating rooms running 5 days a week; divided between those three areas (Table 1). In addition, there were two anaesthetists providing anaesthesia to areas outside the operating rooms including the lithotripsy unit, endoscopy unit, interventional radiology unit, radiotherapy unit, and radiology. We also had two anaesthetists scheduled in the preanaesthesia clinic and one anaesthetist covering the Acute Pain Service (APS).

The anaesthesia and critical care department at KAUH did not only provide health-care services, they are a department in a major academic centre. Medical students attend an anaesthesia rotation during the 5th year of medical school. In 2019, a total of 467 medical students rotated through our department. Our department also participates in training residents and fellows enrolled in the Saudi Council of Health Specialties (SCFHS) programs. During the 2018/2019 academic year, we trained 122 anaesthesia residents and 14 critical care residents. In the interest of encouraging bestpractice anaesthesia, the anaesthesia staff attended a weekly departmental grand round. This article presented the various aspects of King Abdulaziz University Hospital's Anaesthesia and Critical Care department's COVID-19 adaptation plan. We will also discuss the obstacles and challenges faced on the way.

\section{Subjects and Methods Developing a Task Force}

Anaesthesia and critical care department members recognized their essential role in preparing the hospital for the oncoming crisis. They immediately formed an ad hoc COVID-19 committee. The team consisted of members of the anaesthesia and critical care department including anaesthetists, critical care physicians, anaesthesia technicians and members of the department's quality and accreditation committee. The committee's goals were to search and analyse international published reviews and recommendations on dealing with the COVID-19. They would daily review national and international websites for updates in recommendations and guidelines. These resources included the Saudi Ministry of Health (MOH), The Saudi Anaesthesia Society (SAS), The World Health Organization (WHO), The Centre for Disease Control (CDC), The National Health Services (NHS), American Society of Anaesthesiology (ASA), The European Society of Anaesthesia and Intensive Care (ESAIC) and The Lancet's COVID-19 update centre. Any newly identified publications were presented to the committee for review. They were then filtered based on strength of evidence, applicability to our population and availability of resources. The committee would use these to establish a "surge plan" which was made up of internal policies, clinical guidelines and recommendations for managing suspected and confirmed COVID-19 patients as well as protecting the staff and other patients.

Our surge plan covered five major areas. These were infection control, airway team formation, critical care beds expansions, maintaining operating room services and delivering educational duties. 


\section{Infection Control}

The high infectivity rate was of particular concern to anaesthesiologist and critical care physicians as they participate in many aerosol generating procedures. Our goal was to determine how to protect our staff and patients as well as improve hospital staff's familiarity with infection control measures. Our hospital's Infection Control and Environmental Health Unit (ICEHU) provided us with guidelines regarding the appropriate use of Personal Protective Equipment (PPE) for patients with suspected or confirmed COVID-19 according to their risk category. These guidelines were developed by reviewing international guidelines that were adapted to our resources .

\section{The Airway Team}

We were asked by the hospital administration to form an airway team to manage the airway of suspected or confirmed COVID-19 cases in all areas of the hospital. To accomplish this, the COVID-19 committee reviewed the published international recommendations on the management of COVID-19 patient's airway as well as various methods of protecting the staff and limiting disease spread.

\section{The Critical Care Unit}

Our goal was to create a multistage plan to increase the capacity up to four-folds. The intensive care unit in KAUH consists of a 16-bed medical ICU and 10-bed Surgical ICU. We were faced with multiple challenges to achieve our goal with such short notice. The challenges did not only involve the physical space and equipment but it also involved medical, nursing, and support personnel.

\section{Preparing the Operating Room}

We had two challenges to prepare for in the operating room. The first was to prepare for the arrival of COVID19 patients in need of surgery. The second was to decrease the number of surgeries performed daily in order to decrease the opportunity to transmit the virus and conserve our resources in preparation for the surge.

\section{Education}

Our teaching programs at KAUH had to overcome major obstacles during the crisis. On 8th of March, 2020 the Ministry of Education halted all in-class teaching to prevent the spread of the corona virus and discouraged big group gatherings. The King Abdulaziz University's administration followed suit by directing all departments to transform their curriculum into online courses. The following day, the director of undergraduate studies called for an urgent meeting with representatives from all departments in order to address possible solutions and methods of completing the student's training.

KAUH's undergraduate anaesthesia and critical care rotation includes didactic lectures and problem-based learning as well as practical sessions that are taught in the simulation lab as well as in the operating room. Students are assessed based on their participation during classes, demonstrated skills and end-of-rotation exam. In accordance with the university directive, the anaesthesia rotation was transformed into a virtual rotation. The KAUH anaesthesia and critical care team worked on finding an effective method of delivering their curriculum online and compensating for the in-class teaching.

As for the postgraduate training, the KAUH is part of a joint anaesthesia residency program in the Western Region of Saudi Arabia under the Saudi Council for Health Specialties (SCFHS). It is a 5-year program that involves rotations through various subspecialties in anaesthesia and between the different hospitals in the western region of Saudi Arabia. With the beginning of the pandemic, the Director of the Saudi Board of Anaesthesia's Joint Program in the Western Region initiated an urgent online meeting with resident coordinators for all hospitals enrolled in the program. The objective of the meeting was to discuss methods of maintaining the continuity and quality of the training program and ensuring the residents mental and physical wellbeing.

\section{Results}

\section{Developing Protocols}

The COVID-19 anaesthesia and critical care committee had developed a "surge plan". This included all the recommendations, pathways, checklists, staff rota and schedules that aligned with the hospital's surge plan. The anaesthesia and critical care department's surge plan was sub-divided into stages $\mathrm{A}, \mathrm{B}, \mathrm{C}$, and $\mathrm{D}$ to coincide with various levels of the hospital's surge plan (Supplementary 1). The anaesthesia and critical care's surge plan was reviewed and edited regularly by the committee members in response to changing national and international guidelines as well as feedback from the staff. The committee also estimated the necessary resources and equipment required to face the 
Table 2 Procedure Classification According to Risk of Aerosolization

\begin{tabular}{|l|l|}
\hline $\begin{array}{l}\text { Procedures that ARE Considered } \\
\text { Aerosol Generating Procedures }\end{array}$ & $\begin{array}{l}\text { Procedures That Might be } \\
\text { Aerosol Generating } \\
\text { Procedures }\end{array}$ \\
\hline Cardiopulmonary Resuscitation & Nebulizer Administration \\
\hline Endotracheal Intubation & High-Flow Oxygen Delivery \\
\hline Endotracheal Extubation & Tracheostomy \\
\hline $\begin{array}{l}\text { Non-Invasive Positive Pressure } \\
\text { Ventilation (EG, Bipap, CPAP) }\end{array}$ & $\begin{array}{l}\text { Nasal Endoscopy Or } \\
\text { Endoscopic Sinus Surgery }\end{array}$ \\
\hline Bronchoscopy & Flexible Laryngoscopy \\
\hline Manual Ventilation & Transsphenoidal Surgeries \\
\hline Upper GI Endoscopy. & \\
\hline
\end{tabular}

pandemic and placed a request with the hospital administration for procurement.

All department members had been familiarized with the plan through regular virtual meetings and emphasized via email and cell phone messages. Some clinical guidelines, pathways infographics and checklists were also printed and placed in relevant areas near points of care (eg, a diagram on how to doff was hung on the wall in the doffing area). All updates or changes were announced during the department's weekly virtual grand rounds and communicated through internal memos, emails and by using the instant messaging phone application "WhatsApp()" to send instant cell phone notifications to all members of the department.

\section{Infection Control Measures Developing Guidelines}

The high infectivity rate is of particular concern to anaesthesiologist and critical care physicians as they participate in many aerosol generating procedures. As per the ICEHU guidelines, intraoperative procedures were divided into those considered aerosol generating procedures and procedures that may generate aerosols (Table 2). Based on this classification, staff who performed aerosol generating procedures for suspected or confirmed COVID-19 patients were required to wear extended use airborne precautions such as the N95 mask and face protection. Unfortunately, as with many other hospitals, we soon faced a shortage of PPE equipment. In an attempt to conserve PPE, we developed a system of signing out and tracking PPE equipment. Furthermore, the hospital's infection control department developed recommendations on how to sustain and reuse PPE based on published international guidelines. ${ }^{1,11}$

\section{PPE Training and Mask-Fit Test}

The hospital began to provide a 4-hour simulation-based PPE course at its Clinical Skills \& Simulation Centre. This course was designed and run by the anaesthesia and infectious disease department. The Anaesthesia and Critical Care Department ensured all anaesthesiologists, critical care physicians; critical care nurses and anaesthesia technicians promptly attended the course. Also, we ensured that all the department staff underwent a mask fitting test to ensure that everyone wore the appropriate N95 mask design and size.

\section{Airway Team Formation}

By reviewing published COVID-19 articles and guidelines, the department was able to formulate its own clinical pathway and guidelines (Supplementary 2) and a checklist (Supplementary 3) for the airway management team in collaboration with the primary team, intensive care unit, and the respiratory therapists.

Seven airway carts (Figure 1) were assembled containing the appropriate PPE, airway management equipment including a video-assisted laryngoscope and transparent plastic cover sheets to cover the patient and decrease the risk of contamination. These mobile carts were taken with the team to the location that required intubation.

This team consisted of an anaesthesiologist and an anaesthesia technician who were responsible for checking and restocking the carts at the beginning of their shifts. Upon receiving a call, the anaesthetist took a brief history over the phone. The airway cart and video laryngoscope were retrieved from their designated location in the main operating rooms and the required medications were taken from our operating room's automated drug dispensers. Upon arrival to the clinical area, the team followed the guidelines regarding the airway management of a COVID19 patient. After completing intubation and ensuring the patient was stable, the patient was handed over to the primary team. Airway team follow-up records were completed by the intubating anaesthesiologist to ease the follow-up of the cases. All reusable equipment was then sent for sterilization following the policy of the central sterile services department (CSSD). The returned airway cart was also disinfected and refilled after each patient in preparation for the next case. 


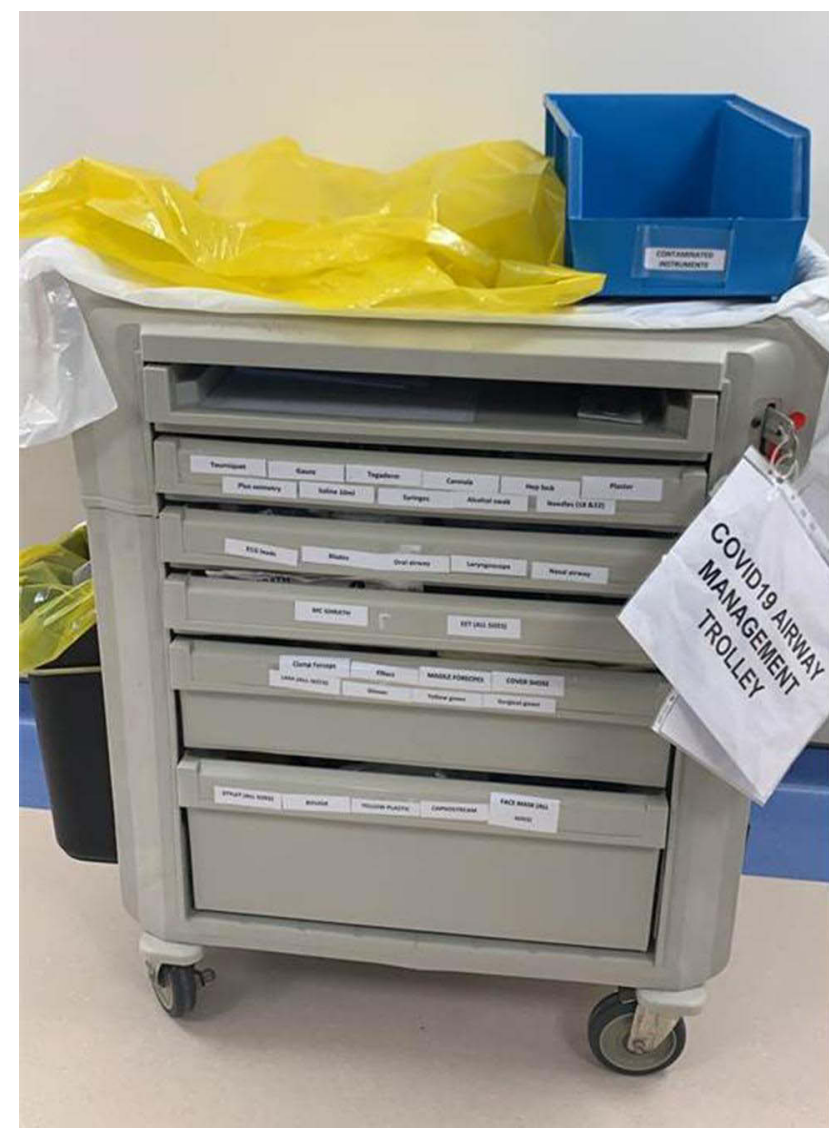

Figure I Airway Cart.

\section{Expanding the Critical Care Unit}

In order to identify possible areas of expansion, a representative group of ICU and anaesthesia physicians identified and toured all the possible physical spaces in the hospital including operating rooms, patients' wards, and other potential spaces to determine their suitability. After choosing the suitable spaces, a request was sent to the medical engineering department to check the readiness to turn those spaces into a critical care unit. We made an inventory of the essential equipment to determine if we need to purchase or redistribute them to allow us to expand. An urgent request was sent to the purchasing department to acquire the essential equipment like additional high-flow oxygen flow cannulas, ventilators, cardiac monitors, suction devices and other tools and supplies.

Regarding staffing, we requested from all non-frontline departments to provide us with a list of volunteer physicians to prepare them to work in ICU. A plan to cover the needed extra staff by anaesthesia physicians has been made. Residents from other departments also joined the ICU and were a crucial part of the team. Previously, in our institute, all codes and floor intubations were covered by ICU staff. The nursing administration made multiple changes aiming to increase the pool of

Table 3 The weekly Operating Room Schedule Prior to the COVID-19 Pandemic*

\begin{tabular}{|c|c|c|c|c|c|c|c|}
\hline DAY & OR I & OR 2 & OR 3 & $\begin{array}{l}\text { EMER } \\
\text { I }\end{array}$ & $\begin{array}{l}\text { EMER } \\
2\end{array}$ & AOS I 0800-1530 & $\begin{array}{l}\text { AOS } 20930- \\
1200\end{array}$ \\
\hline \multirow[t]{2}{*}{ SUN } & \multirow[t]{2}{*}{ NEURO } & PLASTIC & \multirow[t]{2}{*}{ GS } & \multirow[t]{2}{*}{ ER } & \multirow[t]{2}{*}{ OB ER } & \multirow[t]{2}{*}{ ESWL } & \multirow{2}{*}{$\begin{array}{l}\text { RADIOTH } \\
0930-1200 \mathrm{H}\end{array}$} \\
\hline & & PEDIA & & & & & \\
\hline MON & THORACIC & HAEMA & CARDIAC & ER & OB ER & END & $\begin{array}{l}\text { RADIOTH } \\
0930-1200 \mathrm{H}\end{array}$ \\
\hline TUE & ENT & ORTHO & GS & ER & OB ER & $\begin{array}{l}\text { VASCULAR/CARDIAC } \\
\text { ELECTROPHYSIOLOGYIIR }\end{array}$ & $\begin{array}{l}\text { RADIOTH } \\
0930-1200 \mathrm{H}\end{array}$ \\
\hline WED & VASCULAR & GYNE & UROLOGY & ER & OB ER & IR (PEDIA) & $\begin{array}{l}\text { RADIOTH } \\
0930-1200 \mathrm{H}\end{array}$ \\
\hline \multirow[t]{2}{*}{ THU } & \multirow[t]{2}{*}{ NEURO } & ENT & \multirow[t]{2}{*}{ CARDIAC } & \multirow[t]{2}{*}{ ER } & \multirow[t]{2}{*}{ OB ER } & \multirow[t]{2}{*}{ ESWL } & \multirow{2}{*}{$\begin{array}{l}\text { RADIOTH } \\
0930-1200 \mathrm{H}\end{array}$} \\
\hline & & OMFS & & & & & \\
\hline
\end{tabular}

Abbreviations: *CAR, Cardiac Surgery; CATH, cardiac catheterization lab; ER, Emergency surgery; END, endoscopy unit; ENT, Otolaryngology surgery; ESWL, Electronic shock wave lithotripsy unit; GS, general surgery; GYNE, gynaecology; HEAM, Haematology oncology; IR, Interventional radiology; MRI, magnetic resonance imaging; NEURO, Neurosurgery; OB, Obstetrics; OMF, Oromaxillofacial; ONC, oncology; OPTHA, Ophthalmology; ORTHO, Orthopaedics; PEDIA, Paediatric Surgery; PLAS, Plastic surgery; PVT, Patient from the Private Hospital; STAFF, surgery for hospital staff; THOR, Thoracic surgery; VASC, vascular surgery. 


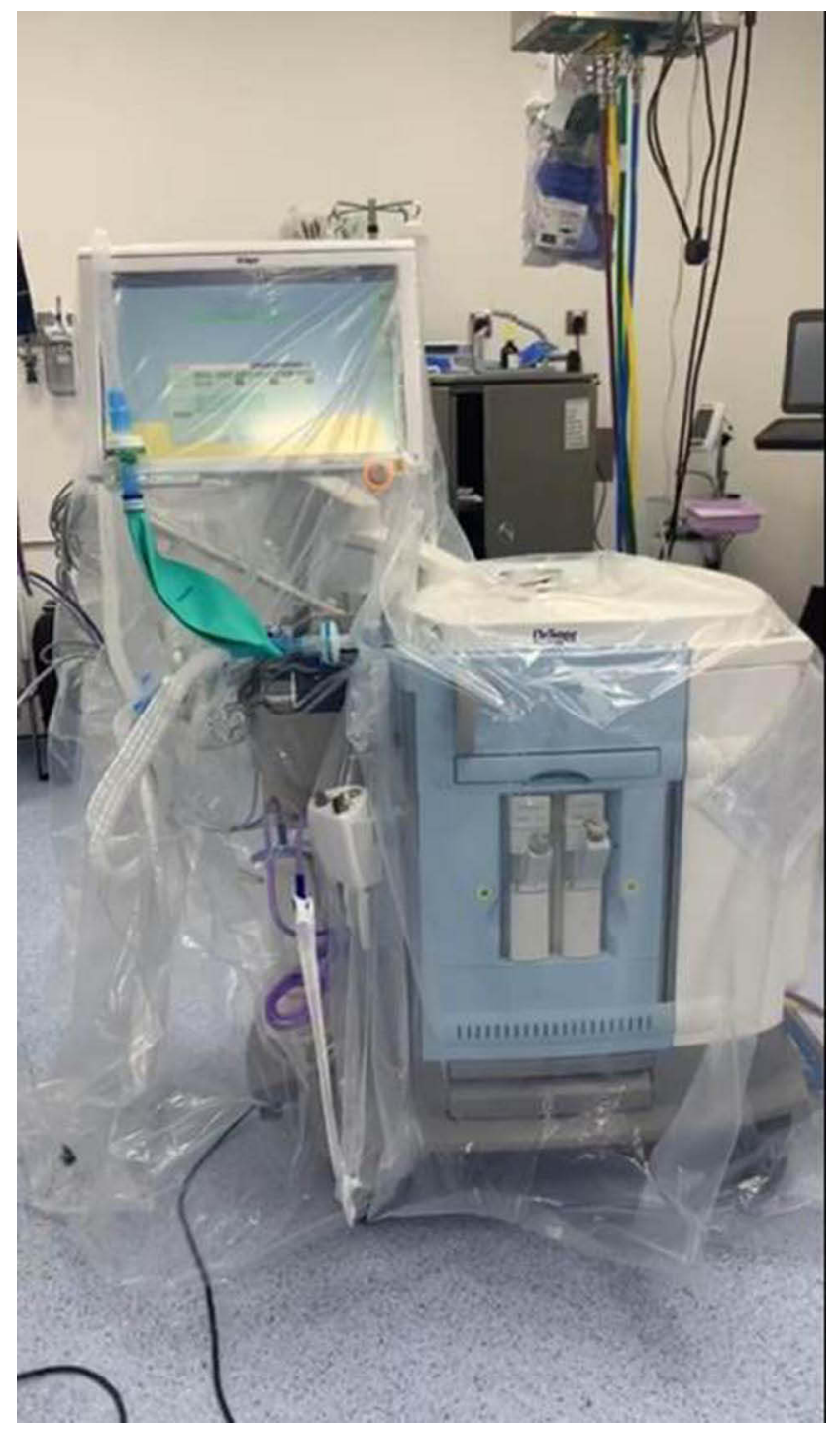

Figure 2 Anaesthesia for a COVID-19 patient. All equipment in the operating room were covered with a plastic drape to decrease contamination.

available nurses by mixing the non-critical care nurses with critical care nurses to act as mentors before the surge of COVID-19 cases.

\section{Preparing the Operating Rooms} Reduction of the Operating Room Services

By the third week of March, hospital administration suspended all elective surgeries allowing only the emergency, cancer and urgent surgeries to go ahead. In the main surgical suit, the number of running operating rooms was decreased from 14 to only 4 (Table 3) Two of the 16 operating rooms were designated for COVID-19 patients.

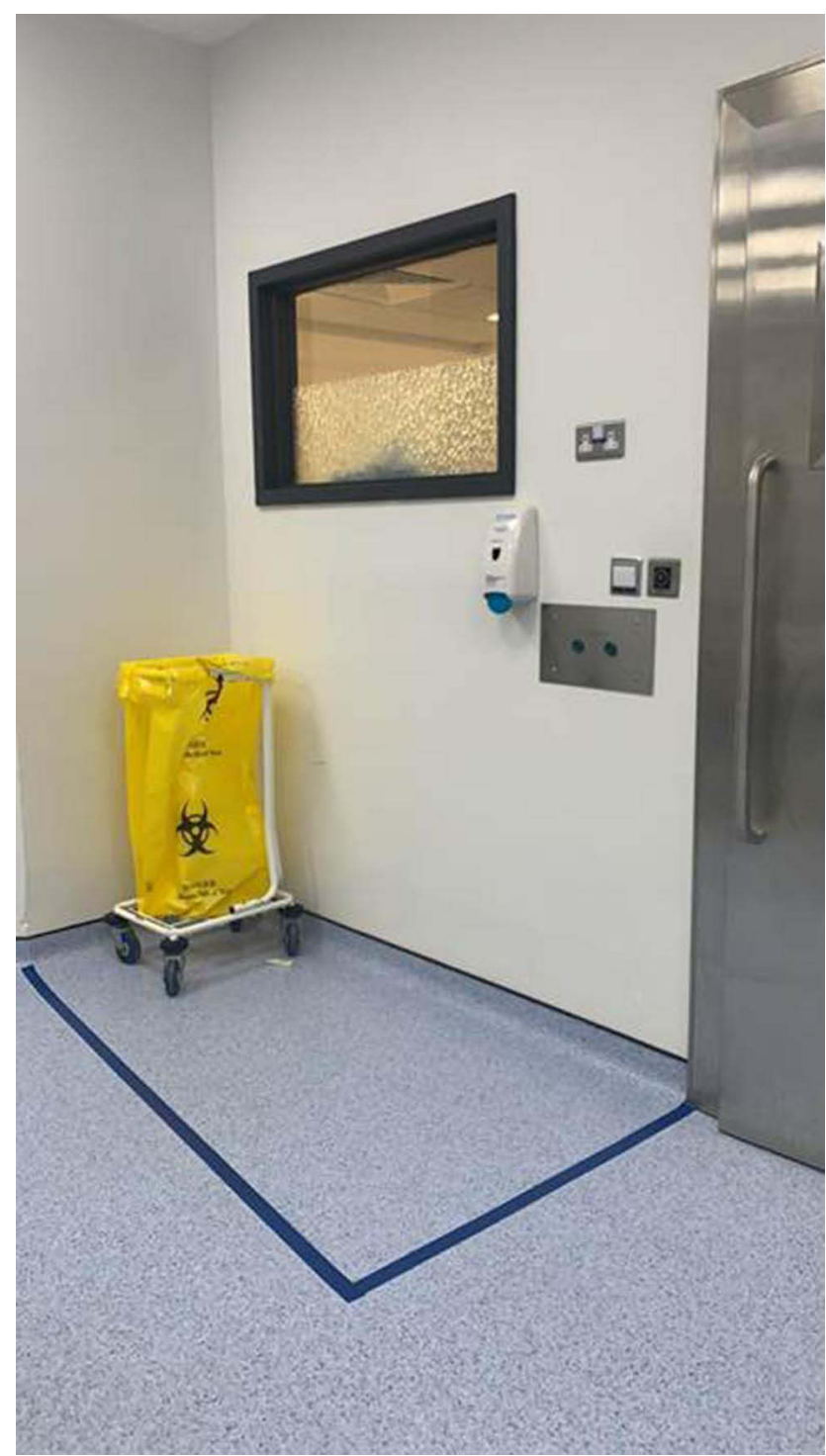

Figure 3 Doffing area in the operating room.

The day surgery unit was closed and the labour and delivery unit continued to operate on non-COVID-19 patients. A designated isolation room was assigned for women in labour who were suspected or confirmed to have COVID19. If they required a caesarean section, it was performed in one of the two designated COVID-19 operating rooms.

The drop in number of operating rooms allowed us to divide our staff of anaesthetists, anaesthesia residents and technicians into two separate teams, team A and team B. In order to decrease the risk of burnout and cross-contamination, only the essential personnel were requested to come in and each team worked one week and rested the following week. 


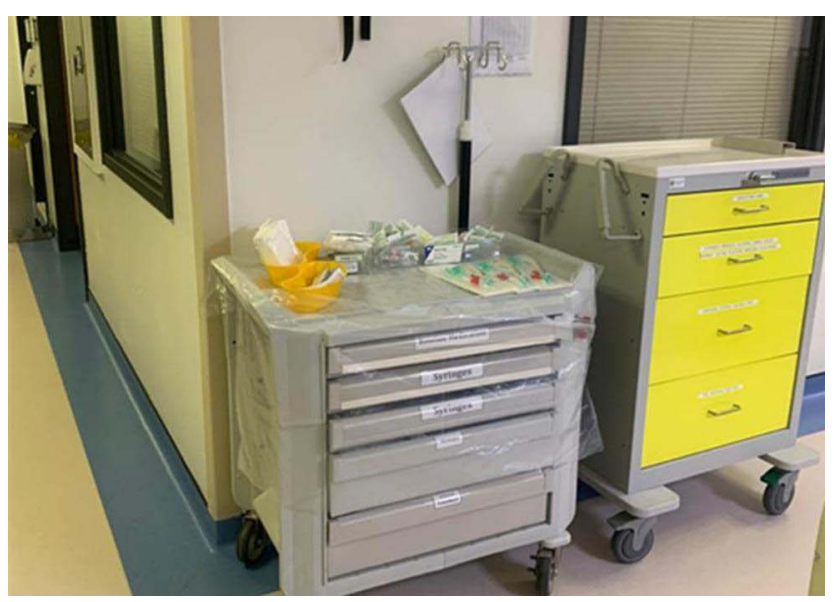

Figure 4 Carts placed outside the negative pressure room containing anaesthesia and PPE equipment.

\section{Assigning and Operating Room}

At the start of the pandemic, two operating rooms in the main operating area were designated for all surgeries on suspected or confirmed COVID-19 cases. The number of equipments in those rooms was limited to only the essentials. That included the anaesthesia machine, operating bed, and a few mayo stands for the anaesthesia and surgical instruments. Both the anaesthesia machine and computer were covered with a clear plastic drape to prevent contamination (Figure 2). Inside the OR, a doffing area was marked on the floor and the poster that illustrated the steps for proper

Table 4 Anaesthesia team roles during surgery on a COVID-19 Patient

\begin{tabular}{|c|c|}
\hline $\begin{array}{l}\text { Primary } \\
\text { anaesthesiologist }\end{array}$ & $\begin{array}{l}\text { Team Leader } \\
\text { - Performs the tracheal intubation and } \\
\text { all airway management. } \\
\text { - Take medical decisions. }\end{array}$ \\
\hline $\begin{array}{l}\text { Anaesthesia technician/ } \\
\text { Assistant: }\end{array}$ & $\begin{array}{l}\text { - Assist the primary anaesthetist with } \\
\text { airway management. } \\
\text { - Assist with drawing up and adminis- } \\
\text { tering medications. } \\
\text { - Assist with patient monitors and IV } \\
\text { lines. }\end{array}$ \\
\hline $\begin{array}{l}\text { Outside Room anaesthesia } \\
\text { technician (Runner) }\end{array}$ & $\begin{array}{l}\text { - Stands outside the operating room. } \\
\text { - Passes equipment to the anaesthesia } \\
\text { team in the room. }\end{array}$ \\
\hline $\begin{array}{l}\text { Outside Room } \\
\text { anaesthesiologist: }\end{array}$ & $\begin{array}{l}\text { - Coordinates with the multidisciplin- } \\
\text { ary team and provides help if } \\
\text { needed. }\end{array}$ \\
\hline
\end{tabular}

doffing was hung on the wall (Figure 3). All other surgeries for non-COVID-19 patients were performed in the remaining operating rooms away from the two designated COVID19 operating rooms to prevent cross infection.

All the operating rooms at KAUH are positive pressure rooms. There is one negative pressure room in the postoperative recovery unit used for highly infectious cases. This negative pressure room was allocated as an induction and extubating room of COVID-19 confirmed and suspected patients. Two carts with PPE and anaesthesia equipment were placed outside this room (Figure 4).

\section{Protocol for the Anaesthesia of COVID-19 Patients}

Once surgery was planned for a confirmed or suspected COVID-19 patient, a team meeting was held to ensure everyone understood the plan for anaesthesia and surgery. In an effort to minimize the number of staff exposed to a COVID19 patient, only the essential staff were permitted inside the operating room and they all received their breaks prior to the patient's arrival. The anaesthesia team consisted of one anaesthetist and an anaesthesia technician inside the operating room and a runner outside the operating room (often another anaesthesia technician) tasked with retrieving any required anaesthesia equipment (Table 4).

To minimize the risk of virus aerosolization during bag-mask ventilation, anaesthesia induction was performed using rapid sequence induction (Table 4). Once the tube's position was confirmed, the patient was transferred directly to the operating theatre via an assigned route. At the end of the surgery, the patient is transferred back to the negative pressure room for extubation.

\section{Testing the Protocols}

It was crucial to test any newly implemented clinical protocol. With the cooperation of The Anaesthesia and Critical Care Department and The Clinical Skills \& Simulation Centre, we conducted a total of 6 simulation drills between 16th March and 23rd April. The simulation drills took place in the following sites: the main operating theatres, the induction room, labour and delivery unit, the intensive care unit, and the post-operative care unit. We tested our operating room setup and protocols via multiple COVID-19 simulation drills. During these simulations we evaluated the practicality of the setup, plan, team knowledge, and team dynamics. These simulations were necessary to familiarize all operating room teams with the 
protocols and to detect possible obstacles, opportunities for contamination and the estimated time required for every step. Furthermore, it tested the teams' preparedness to face a COVID-19 surge. After termination of the scenarios, participants took part in a debriefing session. These debriefing sessions enabled us to identify unexpected problems and obstacles. The findings were used by the anaesthesia and critical care department's COVID-19 Crisis Committee to modify and adjust the protocols.

\section{Academic Duties \\ Undergraduate Education}

Four members of the anaesthesia team attended an intensive course on how to use the university online educational platform Blackboard Ultra ${ }^{\circledR}$. The team subsequently trained the rest of the department teaching staff. All didactic sessions were given to each cohort live via different online platforms. These online platforms included Zoom ${ }^{\circledR}$ and Blackboard Ultra ${ }^{\circledR}$. We had 163 medical students, (out of 488) to teach during the pandemic. The practical sessions were transformed into problem-based learning sessions. The students were divided into groups of ten. The day before each practical session, each group was sent reading material and online videos demonstrating a skill to be discussed. The skills were reviewed the next day with a moderator using one of the online video platforms. For the end-of-rotation exam, the students were first given a mock exam to trial the online program and ensure that the students and examiners were familiar with the testing program. Later, all the students were successfully tested using the online exam software Blackboard ${ }^{\circledR}$. A member of the information technology (IT) department attended the genuine exam to assist with any difficulties. The student's grades were based on their in-class participation in both the didactic and practical sessions as well as their performance in the exam.

\section{Postgraduate Education}

We had sixteen anaesthesia residents training at our centre during the pandemic. The COVID-19 crisis provides several unique learning opportunities but it also decreases their routine clinical exposure for several reasons. First of all, the decrease in elective procedures led to a decrease in workload especially anaesthesia subspecialty cases (chronic pain, thoracic, regional, neurosurgery). Second, in order to prevent viral spread, all rotations between hospitals were stopped. In response, all subspecialty and none-anaesthesia rotations were transformed into a single "COVID-19" rotation. Third, there was an increase in COVID-19 infected and suspected patients. As mentioned previously, only the essential personnel would be in the room during the surgery. ${ }^{12}$ That meant for their own safety anaesthesia residents were unable to participate in anaesthetic care of COVID-19 patients. Fourth, many residents were removed from their anaesthesia rotation and recruited to the medical and emergency department to assist with the care of the increasing number of critically ill patients. In order to maintain the residents' anaesthesia training, we utilized this time to strengthen their non-clinical skills such as management, and leadership, as well as research planning and appraisal. They were encouraged to maintain a detailed log-book and weekly case discussions were conducted using online video platforms. These were all used to assist in evaluation and feedback on their performance.

\section{Anaesthesia Department Education}

Guidelines are constantly being updated based on learned experiences, resources, patient load and new literature being published about the virus. It was essential to keep all members of the anaesthesia department and the rest of the hospital up-to-date. The department used a messaging platform's group chat (WhatsApp(C) that included all members of the department and residents to communicate new protocols, guidelines and shared experiences. Subgroups were formed with hospital administration to streamline information. The grand rounds were continued using the online platform Zoom $($. During these rounds the residents would discuss new and emerging research pertaining to the virus and relevant to our specialty. The grand rounds were also used to familiarize the staff with new protocols, equipment, displaying instructional videos, and to discuss evolving issues.

\section{Research and Quality Improvement}

The KAUH anaesthesia and critical care department recognized its duty as an academic institution to contribute to the developing body of evidence around the COVID-19 virus. This involved collected data surrounding both COVID-19 patients and the healthcare staff taking care of them. The patient data they collected included disease presentation, progress, response to treatment and outcomes. Data collected around staff included staffs' wellbeing, stress level, concerns, team dynamics and infectivity rate. We plan to use that information to help improve 
our understanding of the disease and its effect on the healthcare system, especially on a local level.

Furthermore, the anaesthesia and critical care department took a leading role in preparing the rest of the hospital staff for the COVID-19 crisis. They played an active part in designing a conducting the COVID-19 PPE courses as well as the clinical aspect of the COVID-19 Critical Care Crash Course (5C Course) for non-critical care physicians.

\section{Discussion}

With the arrival of the new COVID-19 pandemic, healthcare systems found themselves in uncharted waters trying to stay afloat. The world watched as images of hospitals in China and Italy overflowed with critical patients and exhausted healthcare staff tried to cope with the sudden surge. Hospitals cannot face this kind of threat alone. A problem of this size requires cooperation between hospitals and local governing bodies. The delay in the case rise in Saudi Arabia may be attributed to the quick response of the Saudi Ministry of Health to the threat by instating strict protocols in an attempt to limit the spread. These actions have bought the health services time to better prepare its healthcare workers and institutes to face the approaching challenges.

Early on in the pandemic the Ministry of Health with the help of other governing bodies put in place several measures to help combat disease spread and expedite treatment. On the 3rd of March, Saudi Arabia reported its first coronavirus case, a citizen coming from Iran. ${ }^{13}$ By mid-March, schools had been closed, air-travel stopped and areas of public gathering such as cinemas, malls and religious gathering had been suspended. Further measures included instituting a strict curfew for all members of the public except essential workers who required a permit to travel. In the interest of identifying and treating cases as early as possible, the government announced free healthcare for everyone. ${ }^{14}$ The aim of these measures was to slow the rate of increase in the number of COVID-19 cases and "flatten the curve".

The KAUH anaesthesia and critical care department were working towards a challenging aim. It included preventing disease spread, protecting staff and maintaining a high quality of healthcare for all patients. This required a delicate balance of isolating affected patients to protect healthcare workers and other patients while attempting to continue providing perioperative services to all types of patients in the hospital. Our protocols were built based on international guidelines and recommendations adjusted to our own resources and the Ministry of Health's recommendations. We frequently changed the protocols in response to changing situations, feedback, guidelines, patient load and unexpected problems. An example of an unexpected problem was the shortage of operating room scrub suits. Many staff had decided to switch to wearing scrubs instead of their regular clothes in the hospital. The scrubs were returned to the hospital at the end of the shift to be washed, therefore decreasing the risk of transmitting the virus home on their clothes to their families. This puts a large unanticipated strain on the laundry service. It is understandable that one of the big concerns of the healthcare staff was keeping themselves and their families safe.

As previously mentioned anaesthesiologists and critical care physicians play an essential role in the fight against COVID-19 and that role increased their exposure to the virus. A study out of China revealed $3.5 \%$ of healthcare personnel were infected, $14.8 \%$ of those had a severe infection and carried a $0.3 \%(n=5)$ mortality. ${ }^{15}$ By the end of March, 12.5\% ( $\mathrm{n}=190)$ of cases in Saudi Arabia were healthcare workers. ${ }^{18}$ Many countries were compelled to alter their surgical practices and even postpone many elective and semi-urgent surgical procedures. ${ }^{16,17}$ At our centre, elective procedures had been postponed in order to decrease disease transmission and conserve resources. This allowed us more flexibility in order to decrease the number of staff coming into the hospital on a daily basis, therefore reducing the risk of cross contamination and burnout. Unfortunately, this delay in elective procedures taking place all over the world will have

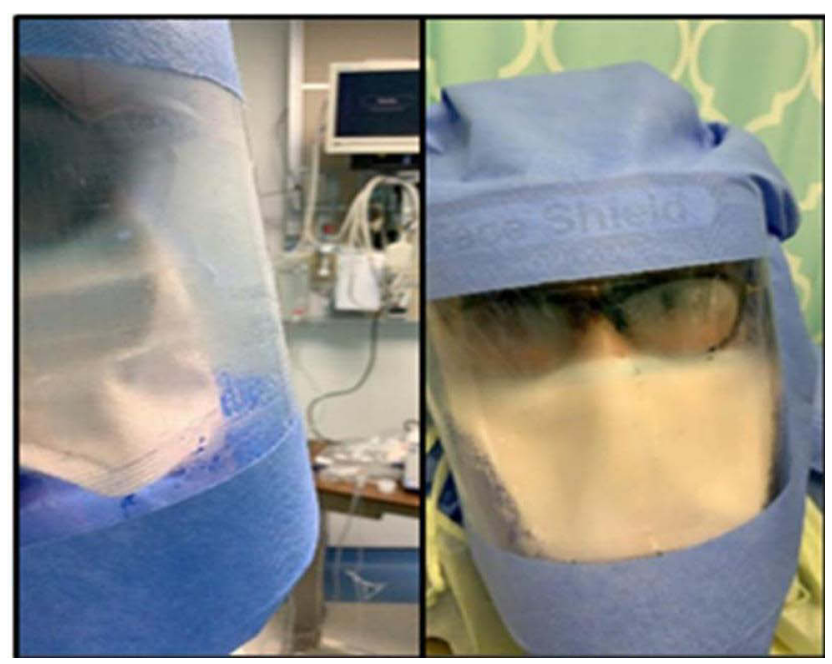

Figure 5 Protective hood would fog up with perspiration after a few minutes of being worn. 
devastating consequences on an already overburdened health system. It is estimated that 28 surgical operations will be cancelled in the US alone. This blockade will possibly take more than a year to clear if surgical teams work at $120 \%$ capacity. ${ }^{18}$

The department also ensured the team had proper access to PPE and training on how to correctly use it. At the start of the pandemic, full PPE was reserved for suspected/confirmed COVID-19 patients. Eventually, in response to multiple incidences of asymptomatic patients being diagnosed after surgery with COVID-19 as well as a change in international guidelines, staff had been instructed to wear full PPE during all anaesthesia inductions and extubations. ${ }^{19}$ Like many other countries, we were facing a shortage of PPE. The powered airpurifying respirator (PAPR), which has been used at several hospitals in Wuhan, was not available at our hospital. Instead, we had been supplied with a "hood" with a clear plastic screen for physicians who have failed the N95 mask fit test. Unfortunately, this "hood" sometimes fogged up after a few minutes of wear limiting vision (Figure 5). Also, some staff experienced severe claustrophobia upon wearing the "hood" and many felt PPE affected their decision-making skills. As of yet, we have not found an alternative and we are in constant communication with hospital administration to do so. Our struggle with PPE mirrors similar experiences in other countries facing the pandemic. $^{20,21} \mathrm{We}$ are in continuous contact with the infection control department on how to better manage special situations and staff contact with suspected patients.

The airway team was a newly implemented service at our hospital. Protocols involving the airway team were constantly being revised and adjusted based on feedback from the team and other departments. When it was first implemented, another member of the anaesthesia staff would accompany the airway team to their destination to observe, offer help and assist with the debriefing. One of the biggest challenges that faced the airway team was responding to calls in unfamiliar wards and being assisted by staff that had various levels of experience with intubation. Due to the increasing number of critical patients, nurses from other wards such as obstetrics, surgery and paediatrics had been recruited to work in the isolation wards and ICU where many COVID-19 patients were intubated. Another problem was communication between the anaesthetist preforming the procedure and the outside runner. Their voice was often muffled by the N95 mask and protective hood. We solved this by placing a phone in the intubating anaesthetist's shirt pocket and setting it to speaker mode. We also used Bluetooth ear phones when available. These methods were tested out during simulation drills. When managing these fragile patients, clear and direct communication was essential.

Simulated COVID-19 cases played an invaluable role in designing and implementing hospital protocols. The use of simulation in healthcare has proven to be an effective tool to safely modify attitudes, clinical skills and teamwork behaviours that are often encountered in high-risk environments. $^{22-24}$ In hospitals across China, drills were held to ensure the optimal management of emergencies, with mandatory multidisciplinary participation across anaesthesia, surgery, critical care, paediatrics, and obstetrics. $^{25}$ Similar experiences, utilizing simulation team training, have been later reported from North American and European health care systems. ${ }^{26,27}$ It had already been used during this pandemic to trial various barriers to viral spread during intubation and PPE use. ${ }^{28-30}$ It is also imperative that we test the logistics and practicality of newly implemented protocols. Testing the protocols in a controlled environment allowed us to detect possible obstacles and provide expert advice to unexpected problems. The simulation drills provided information on how to stock the COVID-19 operating and induction room, how and with whom to communicate, how to dispose of infected items as well as an estimated time for every step related to operating on a COVID-19 patient. Examples of the problems identified were difficulties in verbal communication while wearing full PPE, traffic inroute to the operating room, storage of patient's transport bed during surgery and unnecessary connection and disconnection of monitors. All these observations had been addressed and used in adjusting our protocols.

Reliance on online technology has vastly expanded since the beginning of the pandemic. These safety measures brought on big challenges to teaching institutes that have been dependent on hands-on training. Academics began exploring new and innovative methods of teaching using online platforms and teaching programs, which they may never have considered if it was not for the pandemic. This new experience had definitely encouraged staff to become more creative and look out-side-the-box when designing their lectures. Although hands-on teaching is an indispensable part of anaesthesia training and would probably return when it's safe to do so, after the COVID-19 experience, academics might be more comfortable incorporating interactive online programs into their teaching plan. 
Having a department WhatsApp $\odot$ group made it very easy to inform all members of the department about sudden changes in protocols and share new information. The ease of using the group chat meant that there was often abombardment of posts and replies making it difficult to identify the more urgent ones. The department ensured that the most important messages got through by sending them via email, posting them in the group, as well as reminding members during the department's weekly online meetings. Online meeting platforms brought with them the convenience of setting up meetings from the comfort of your own home. Consequently, meetings did not have to be restricted to working hours when all staff was available on site. They could be scheduled at any time of theday, disturbing the staff's worklife balance. It has already been shown that work-related use of technologies after hours can lead to emotional exhaustion which may exacerbate the stress caused by the pandemic. ${ }^{31}$

This pandemic had taught us the importance of shared experiences and expertise. There is no doubt that the information shared by healthcare workers in the first hit countries such as China, Italy and the UK played an invaluable role in saving millions of lives across the globe. Their knowledge is being used to treat patients, design healthcare strategies and manage resources in both our institute and others. Both international and local webinars have helped answer questions and share emerging knowledge of this new adversary. Although our hospital has been involved in managing both the Ebola and MERS outbreak, the COVID-19 provides a unique challenge due to its rapid spread causing a sudden large patient load. Even within our own hospital, unanticipated hazards and obstacles were avoided by communicating with other members of the department, trainees and other departments in the hospital.

The sharing of knowledge among interdisciplinary committees including anaesthesia, nursing, surgery, infectious disease and administration has helped formulate effective protocols. However, our knowledge of the virus is still evolving. It is essential that these protocols are regularly revised and adjusted according to new knowledge and guidelines. Concerns of health workers should be transmitted to department decision makers and used to plan support services and protocols. It is also important to identify resident and trainee concerns and ensure that they feel well supported in this turbulent environment. Communication should not be limited to within the hospital alone, it is important that we share our knowledge with other hospitals, the government and the public. This will help guide safety measures, resource management, spending, public behaviour and trust. We hope that our shared experience helps others during this pandemic and assists in building stronger healthcare systems for the future.

In conclusion, it is essential that hospitals develop individualized health-crisis response plans based on their type of institution and the available knowledge and resources. These plans will then require testing and frequent revisions and adjustments. Our current plan has undergone many alterations and we hope that our shared experience will benefit other institution just as we have benefited from others. We are now at the beginning of July; we have yet to find out how and when this pandemic will end. We, as healthcare workers, are in it for the long haul. We have all gone out of our comfort zone to try new things and take risks. It is critical that we work together, plan ahead and try to anticipate and prepare for all possible outcomes. This will involve hard work, good communication and continuously re-evaluating our goals and protocols. We hope at the end of the pandemic we can all look back with pride at what we have accomplished.

\section{Abbreviations}

CFR, Case Fatality Rate; COVID-19, Coronavirus Disease caused by SARS-COV-2; CPAP, Continuous Positive Airway Pressure; ETT, endotracheal tube; ICU, intensive care unit; ICEHU, infection control and environmental health unit; KAUH, King Abdulaziz University Hospital; L\&D, labour and delivery; NIPPV, Non-invasive positive pressure ventilation; OR, operating room; PACU, Post anaesthesia care unit; PAPR, powered air-purifying respirators; PPE, Personal protective equipment; WHO, World Health Organization.

\section{Ethical Considerations}

This is a purely descriptive study; therefore, it was exempt from the ethical approval.

\section{Acknowledgments}

The authors would like to thank all staff of Anesthesia and Critical Care department for their support and cooperation during the COVID-19 Pandemic Plans.

\section{Disclosure}

The authors report no conflicts of interest in this work.

\section{References}

1. Rajnik M, Cascella M, Cuomo A, Dulebohn SC, Di Napoli R. Features, evaluation, and treatment of coronavirus (COVID-19). Uni Serv Univ Health Sci. 2021. 
2. Organization WH. Coronavirus disease 2019 (COVID-19): situation report. 86; 2020.

3. Hua J, Shaw R. Corona virus (Covid-19)"infodemic" and emerging issues through a data lens: the case of china. Int J Environ Res Public Health. 2020;17:2309. doi:10.3390/ijerph17072309

4. Baud D, Qi X, Nielsen-Saines K, Musso D, Pomar L, Favre G. Real estimates of mortality following COVID-19 infection. Lancet Infect Dis. 2020;20:773. doi:10.1016/S1473-3099(20)30195-X

5. Lai -C-C, Shih T-P, Ko W-C, Tang H-J, Hsueh P-R. Severe acute respiratory syndrome coronavirus 2 (SARS-CoV-2) and coronavirus disease-2019 (COVID-19): the epidemic and the challenges. Int $J$ Antimicrob Agents. 2020;55:105924. doi:10.1016/j. ijantimicag.2020.105924

6. Guan WJ, Z-yi N, Hu Y, et al. Clinical characteristics of coronavirus disease. 2019;1708-1720.

7. Armocida B, Formenti B, Ussai S, Palestra F, Missoni E. The Italian health system and the COVID-19 challenge. Lancet Public Health 2020;5:e253. doi:10.1016/S2468-2667(20)30074-8

8. Legido-Quigley H, Mateos-García JT, Campos VR, Gea-Sánchez M, Muntaner C, McKee M. The resilience of the Spanish health system against the COVID-19 pandemic. Lancet Public Health. 2020;5: e251-e2. doi:10.1016/S2468-2667(20)30060-8

9. Willan J, King AJ, Jeffery K, Bienz N. Challenges for NHS hospitals during covid-19 epidemic. Br Med J Publ Group. 2020. doi:10.1136/ bmj.m1117

10. Raboud J, Shigayeva A, McGeer A, et al. Risk factors for SARS transmission from patients requiring intubation: a multicentre investigation in Toronto, Canada. PLoS One. 2010;5:e10717. doi:10.1371/ journal.pone.0010717

11. Planning P. Recommended guidance for extended use and limited reuse of N95 filteringfacepiece respirators in healthcare settings. US Government. 2020.

12. Bahaziq W, Tayeb B, Alzoraigi U, Boker A. Gaps identification in Saudi anesthesia residency training during early time of pandemic: trainee view. Saudi J Anaesth. 2021;15:155. doi:10.4103/sja.sja_1195_20

13. Almalki M, FitzGerald G, Clark M. Health care system in Saudi Arabia: an overview. EMHJ. 2011;17(10):784-793. doi:10.26719/ 2011.17.10.784

14. Awaji MA. Pandemic of coronavirus (COVID-19) in Saudi Arabia. 2020.

15. Novel CPERE. The epidemiological characteristics of an outbreak of 2019 novel coronavirus diseases (COVID-19) in China. Zhonghua Liu Xing Bing Xue Za Zhi. 2020;41:145.

16. DeFazio JR, Kahan A, Fallon EM, et al. Development of pediatric surgical decision-making guidelines for COVID-19 in a New York City children's hospital. J Pediatr Surg. 2020;55:1427-1430. doi:10.1016/j.jpedsurg.2020.05.043

17. Benítez CY, Pedival AN, Talal I. et al. Adapting to an unprecedented scenario: surgery during the COVID-19 outbreak. Revista Do Colégio Brasileiro De Cirurgiões;2020. 47. doi: 10.1590/01006991e-20202701

18. Negopdiev D, Collaborative C, Hoste E. Elective surgery cancellations due to the COVID-19 pandemic: global predictive modelling to inform surgical recovery plans. Br J Surg. 2020;107:1440-1449.
19. Matava CT, Kovatsis PG, Summers JL, et al. Pediatric airway management in Coronavirus disease 2019 patients: consensus guidelines from the society for pediatric anesthesia's pediatric difficult intubation collaborative and the Canadian pediatric anesthesia society. Anesth Analg. 2020. doi:10.1213/ANE.0000000000004872

20. Davey SL, Lee BJ, Robbins T, Randeva H, Thake CD. Heat stress and PPE during COVID-19: impact on healthcare workers' performance, safety and well-being in NHS settings. $J$ Hospital Infect. 2021;108:185-188. doi:10.1016/j.jhin.2020.11.027

21. Benítez CY, Güemes A, Aranda J, et al. Impact of personal protective equipment on surgical performance during the COVID-19 pandemic. World J Surg. 2020;44:2842-2847. doi:10.1007/s00268-020-05648-2

22. Fent G, Blythe J, Farooq O, Purva M. In situ simulation as a tool for patient safety: a systematic review identifying how it is used and its effectiveness. BMJ Simul Technol Enhanced Learning. 2015;1:103-110. doi:10.1136/bmjstel-2015-000065

23. Patterson MD, Geis GL, Falcone RA, LeMaster T, Wears RL. In situ simulation: detection of safety threats and teamwork training in a high risk emergency department. BMJ Qual Saf. 2013;22:468-477. doi:10.1136/bmjqs-2012-000942

24. Patterson MD, Geis GL, LeMaster T, Wears RL. Impact of multidisciplinary simulation-based training on patient safety in a paediatric emergency department. BMJ Qual Saf. 2013;22:383-393. doi:10.1136/bmjqs-2012-000951

25. Parry J. China coronavirus: cases surge as official admits human to human transmission. Br Med J Publ Group. 2020. doi:10.1136/bmj. $\mathrm{m} 236$

26. Dieckmann P, Torgeirsen K, Qvindesland SA, Thomas L, Bushell V, Langli EH. The use of simulation to prepare and improve responses to infectious disease outbreaks like COVID-19: practical tips and resources from Norway, Denmark, and the UK. Adv Simulation. 2020;5:1-10. doi:10.1186/s41077-020-00121-5

27. Dubé M, Kaba A, Cronin T, Barnes S, Fuselli T, Grant V. COVID-19 pandemic preparation: using simulation for systems-based learning to prepare the largest healthcare workforce and system in Canada. $A d v$ Simulation. 2020;5:1-12. doi:10.1186/s41077-020-00138-w

28. Workman AD, Welling DB, Carter BS, et al. Endonasal instrumentation and aerosolization risk in the era of COVID-19: simulation, literature review, and proposed mitigation strategies. Int Forum Allergy Rhinol. 2020:798-805. doi:10.1002/alr.22577

29. Lockhart SL, Naidu JJ, Badh CS, Duggan LV. Simulation as a tool for assessing and evolving your current personal protective equipment: lessons learned during the coronavirus disease (COVID-19) pandemic. Canadian J Anesthesia. 2020;67:895-896. doi:10.1007/ s12630-020-01638-Z

30. Matava CT, Yu J, Denning S. Clear plastic drapes may be effective at limiting aerosolization and droplet spray during extubation: implications for COVID-19. Canadian J Anesthesia. 2020;67:902-904. doi:10.1007/s12630-020-01649-w

31. Xie J, Ma H, Zhou ZE, Tang H. Work-related use of information and communication technologies after hours (W_ICTs) and emotional exhaustion: a mediated moderation model. Comput Human Behav. 2018;79:94-104. doi:10.1016/j.chb.2017.10.023 


\section{Publish your work in this journal}

The International Journal of General Medicine is an international, peer-reviewed open-access journal that focuses on general and internal medicine, pathogenesis, epidemiology, diagnosis, monitoring and treatment protocols. The journal is characterized by the rapid reporting of reviews, original research and clinical studies across all disease areas. The manuscript management system is completely online and includes a very quick and fair peer-review system, which is all easy to use. Visit http://www.dovepress.com/ testimonials.php to read real quotes from published authors.

Submit your manuscript here: https://www.dovepress.com/international-journal-of-general-medicine-journal 